\title{
Erratum to: Titrating droxidopa to maximize symptomatic benefit in a patient with Parkinson disease and neurogenic orthostatic hypotension
}

\author{
Fiona Gupta $^{1} \cdot$ Beverly Karabin $^{2} \cdot$ Ali Mehdirad ${ }^{3}$
}

Published online: 9 September 2017

(C) The Author(s) 2017

\section{Erratum to: Clin Auton Res (2017) 27 (Suppl 1):S15-S16 DOI 10.1007/s10286-017-0430-x}

The article "Titrating droxidopa to maximize symptomatic benefit in a patient with Parkinson disease and neurogenic orthostatic hypotension", written by Karabin et al., was originally published Online First without open access. After publication in volume 27, issue 1, page S15-S16 the author decided to opt for Open Choice and to make the article an open access publication. Therefore, the copyright of the article has been changed to (c) The Author(s) 2017 and the article is forthwith distributed under the terms of the Creative Commons Attribution 4.0 International License (http://creativecommons.org/licenses/by/4.0/), which permits use, duplication, adaptation, distribution and reproduction in any medium or format, as long as you give appropriate credit to the original author(s) and the source, provide a link to the Creative Commons license, and indicate if changes were made.

The online version of the original article can be found under doi:10.1007/s10286-017-0430-x.

Beverly Karabin

Beverly.karabin@utoledo.edu

1 Movement Disorders Center, Hackensack University Medical Center, Hackensack, NJ, USA

2 Syncope and Autonomic Disorders Center, University of Toledo, Toledo, OH, USA

3 Cardiac Electrophysiology Section, Division of Cardiology, Department of Internal Medicine, Saint Louis University, St. Louis, MO, USA 